\title{
Sn and Ti influences on intermetallic phases damage in hot dip galvanizing
}

\author{
V. Di Cocco \\ DICeM - Università di Cassino e del Lazio Meridionale, Via G. Di Biasio 43, 03043, Cassino (FR), Italy \\ v.dicocco@unicas.it
}

\begin{abstract}
Protection against metallic materials corrosion is one of the most important means to reduce both maintenance costs and environmental impact. In the last years new studies on chemical baths compositions and fluxes have been performed in order to improve processes, corrosion resistance and mechanical behavior of $\mathrm{Zn}$ based coatings. Chemical bath composition is often improved by the Sn addition which increases the fluidity of the melt. Ti addition makes the coatings to change color under appropriate heat treatment. In this work a comparative microstructural analysis, in $\mathrm{Zn}-\mathrm{Sn}$ and $\mathrm{Zn}$-Ti coatings, is performed to evaluate intermetallic phases formation kinetics and the influence of intermetallic microstructure on coating damage under constant bending deformation.
\end{abstract}

KeYwORDS. Hot Dip Galvanizing; Intermetallic Phases; Damage.

\section{INTRODUCTION}

$\mathrm{P}$ rinciples of hot dip galvanizing have been unchanged since 200 years, when this coating process came into use. Actually, it is still one of most important processing techniques to protect metallic material against corrosion in many aggressive environments.

New investigations on bath composition were performed to generate different types of coatings depending on specific purposes such as high plastic deformations or reinforced components.

$\mathrm{Zn}$ and $\mathrm{Zn}$-based coating formation is a diffusion driving phenomenon. Many intermetallic phases are generated by different $\mathrm{Zn}$ concentration varying from surface to substrate. Alloying components and their concentrations in the bath influence intermetallic phases formation. These are responsible for a brittle or a ductile coating - because of different phases behaviors and their thicknesses.

Four intermetallic layers are usually observed in traditional $\mathrm{Zn}, \mathrm{Zn}-\mathrm{Pb}$ or $\mathrm{Zn}-\mathrm{Sn}$ coatings, characterized by different $\mathrm{Fe}$ contents (decreasing from steel substrate towards surface). Zinc-based layer formation is obtained by interdiffusion of zinc and iron atoms. This process generates a different chemical composition coating, characterized by different intermetallic phases according with $\mathrm{Zn}-\mathrm{Fe}$ diagram, as shown in Fig. 1a. From the iron-coating interface towards surface, $\mathrm{Zn}$ content increases. Therefore the zinc coating is a multilayer system mainly formed by four phases (Fig. 1b), characterized by different thickness and mechanical properties. Outer layer is a ductile $\eta$ phase with maximum Fe content up to $0.03 \%$. The following layer is named " $\zeta$ " phase, which is isomorphous with a monoclinic unit cell. Its atomic structure contains a $\mathrm{Fe}$ atom and a $\mathrm{Zn}$ atom surrounded by $12 \mathrm{Zn}$ atoms at the vertices of a slightly distorted icosahedron. The icosahedra link together to form chains and the linked chains pack together in a hexagonal array [1]. $\delta$ phase is a brittle one with $\mathrm{Fe}$ content up to $11.5 \mathrm{wt} \%$ and hexagonal crystal structure. The last phase is a very thin layer named " $\Gamma$ " and it is characterized by a $\mathrm{Fe}$ content up to $29 \mathrm{wt} \%$ (fcc). Coating formation is governed by physical (bath 
temperature, immersion time, pre-galvanizing surface temperature, etc.) and chemical parameters (bath and steel chemical compositions, flux chemical composition, etc.).

Processes are very important also on typologies of coatings; eg. in the galvanized steel strip, produced through a continuous hot-dip galvanizing process, the thickness of the adhered zinc film must be controlled by impinging a thin plane nitrogen gas jet [2].
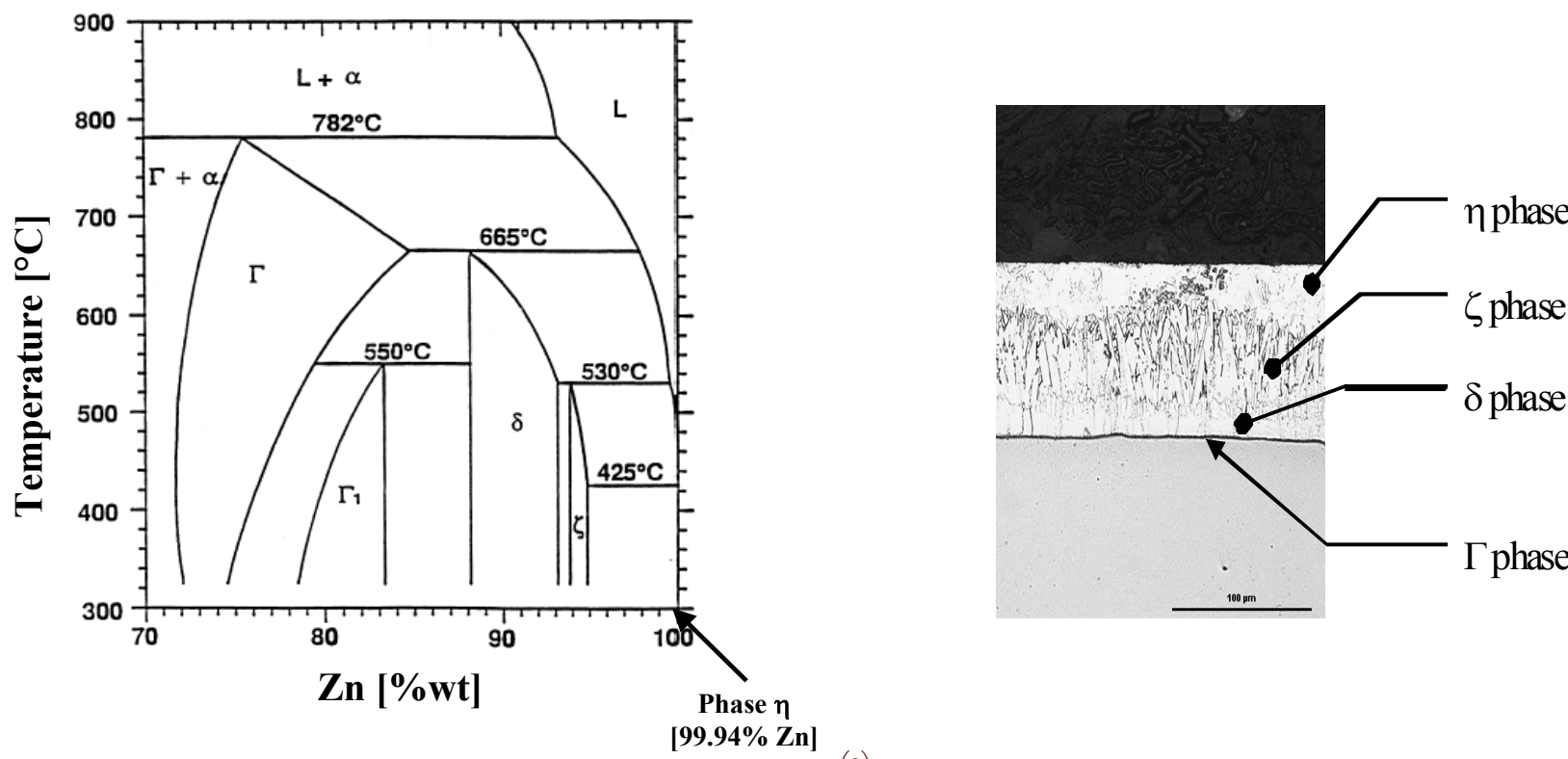

(a)

Figure 1: Intermetallic phases in a traditional hot dip galvanizing coating: a) Zn-Fe status diagram portion [1], b) Morphological aspects of intermetallic phases.

Presence of silicon in the material is very important for coatings formation and its properties. Because of the limited solubility of silicon in the $\Gamma$ layer, an excessive content of silicon in steels accumulates on the surface of substrate. The $\mathrm{Fe} / \mathrm{Zn}$ reaction determines movement of the $\alpha-\mathrm{Fe} / \Gamma$ interface towards the steel substrate. The $\alpha$-Fe phase, rich in silicon and slightly soluble in $\Gamma$ layer, breaks and the particles enters in to $\lambda$ layer through the $\Gamma$ layer. Then silicon-rich $\alpha-\mathrm{Fe}$, dissolving in the $\lambda$ layer, accelerates the growth of the $\lambda$ layer to steel substrate, and the coating becomes loose [3].

When coated steel sheets are subjected to corrosive environments, their corrosion behavior is affected by changes of the coating texture and also by the microstructure. Basal plane texture coefficient increases with the increasing of lead zinc bath content of zinc bath, as well as increases the texture coefficient of high angle pyramidal, low angle pyramidal and prism planes. $\Gamma$ layer thickness is increased by increasing the lead content of the zinc bath. Coatings having a better corrosion resistance are characterized by greater basal texture coefficient and smaller $\Gamma$ layer thickness [4].

To prevent the penetration of the aggressive ion $\mathrm{Cl}^{-}$in outdoor exposition, the presence of oxide under coating is accepted. Moreover the galvanic performance of the coating improves with the presence of $\mathrm{ZnO}$-rich inner alloy layers as also evidenced when polarization studies were conducted with a different approach [3].

In the last years, there has been an increase in zinc coatings research, focusing both on coating procedures and on mechanical behavior characterization, in order to optimize Zn layer thickness and mechanical performances [5].

In this work a traditional $\mathrm{ZnSn}$ bath and an innovative $\mathrm{ZnTi}$ bath were considered to obtain coatings on iper Sandelin steel plate specimens. Bending tests [6-10] were performed to investigate damaging micromechanisms in intermetallic phases.

\section{MATERIAL AND METHODS}

$\mathrm{T}$ wo kinds of $\mathrm{Zn}$-based baths were used in order to generate coatings characterized by different intermetallic phases. It were used a $\mathrm{Zn}-\mathrm{Sn}(3.0 \mathrm{wt} \%)$ bath and a $\mathrm{Zn}-\mathrm{Ti}(0.5 \mathrm{wt} \%)$ bath at $460 \pm 2{ }^{\circ} \mathrm{C}$. For all the investigated Zn-based baths, $3 \mathrm{~mm}$ thick of commercial carbon steel plates were considered. Steel chemical composition is 
shown in Tab. 1. Zn-Sn and Zn-Ti baths were Fe saturated to reproduce industrial conditions.

\begin{tabular}{cccccc}
\hline C & Si & Mn & P & S & Al \\
0.090 & 0.167 & 0.540 & 0.10 & 0.004 & 0.051 \\
\hline
\end{tabular}

Table 1: Galvanized steel chemical composition (wt $\%)$.

Before the galvanization steels samples were polished by degreasing and rinsing with alcohol. Subsequently specimens were dipped in an aqueous solution $50 \% \mathrm{HCl}$ at $25^{\circ} \mathrm{C}$ for 10 minutes, washed in fresh water, fluxed in an aqueous solution containing $280 \mathrm{~g} / 1 \mathrm{ZnCl}_{2}$ and $220 \mathrm{~g} / 1 \mathrm{NH}_{4} \mathrm{Cl}$ at laboratory temperature for 2 minutes and then dried for 10 minutes at $50^{\circ} \mathrm{C}$. Then specimens were dipped for $15,60,180,360$ and 900 seconds.

Bending tests were carried out on the galvanized specimens. They are characterized by $25 \mathrm{~mm}$ of calibrated length in bending angle deformation control up to half-deformation about $34^{\circ}$, which corresponds to a deformed half-angle without load of about $30^{\circ}$ in not galvanized specimen. All the calibrated lengths are characterized by constant values of bending moment at each half-deformation values.

Finally, in order to identify the damaging mechanisms of each investigated coating bath, longitudinal sections of the bended specimens were metallographically obtained and observed by means of an optical microscope (LOM). Damage level was evaluated in terms of "radial cracks density" (cracks number/length) considering 6 images for each specimen (damage level was obtained as the mean value of 24 measurements, with a very high repeatability). Crack paths were also evaluated analysing their interactions with Zn-based intermetallic phases. As a consequence, damage evaluation was considered strongly connected with cracks nucleation: authors are conscious of the limit of this definition that does not take into account the crack growth in the different phases.

\section{RESULTS AND DISCUSSION}

I

n Fig. 2 equilibrium phases diagrams of $\mathrm{Zn}-\mathrm{Sn}$ and $\mathrm{Zn}$-Ti systems are shown. The first diagram indicates a decrease of melting temperature addictioning Sn nearby the eutectic compositions. The second diagram shows that the addition of Ti leads to an increase of melting temperature. It implies the use of a small addition of Ti to avoid troubles in solidification because of the lower temperature of specimen in dipping operations. Furthermore, Zn-Ti diagram is not totally known for high values of Ti yet.

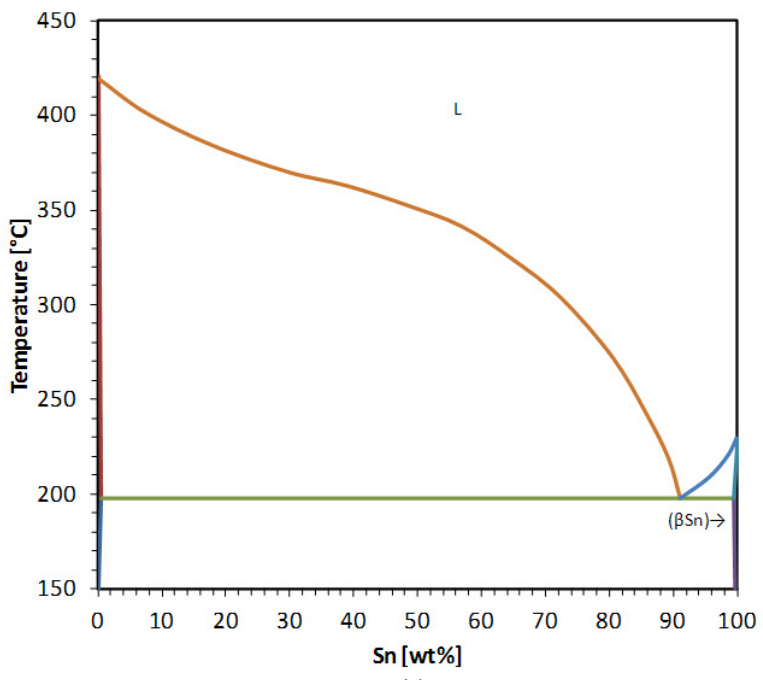

(a)

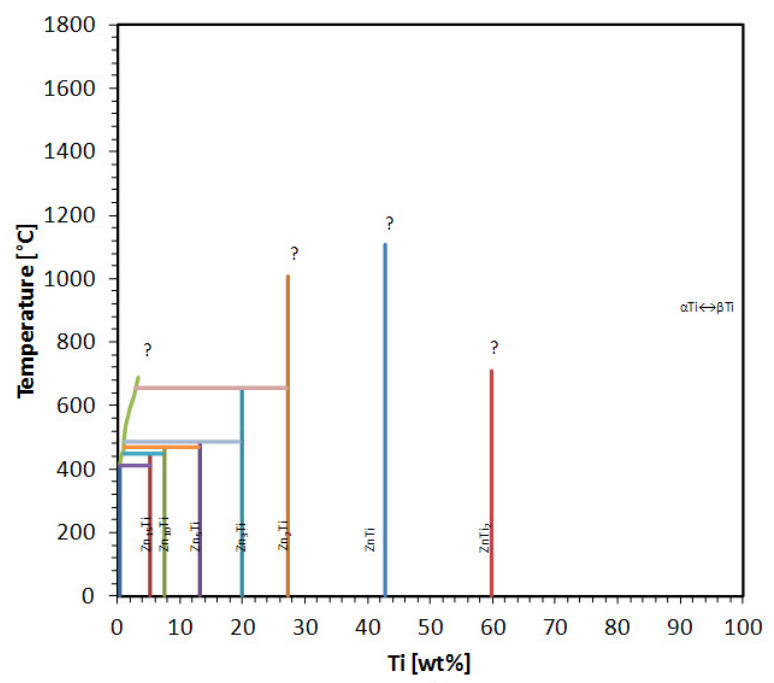

(b)

Figure 2: Equilibrium phases diagrams [11]: a) Zn-Sn alloys, b) Zn-Ti alloys.

Coatings carried out from bath with $\mathrm{Sn}$ and bath with Ti are externally very different. The reason can be found in their different composition and in microstructures. Coatings obtained by $\mathrm{Zn}-\mathrm{Sn}$ bath are characterized by bright smooth 
surfaces as traditional coatings, while coatings obtained by $\mathrm{Zn}$-Ti bath are characterized by high values of roughness, because they are not optimized galvanizing conditions.

Presence of $\mathrm{Sn}$ improves bath fluidity and leads to better surface aspect, being better the wetability of melted $\mathrm{Zn}$-Sn alloy. Furthermore the presence of Ti increases bath reactivity, leading to a not well homogeneous surface.

Behaviors of $\mathrm{Zn}-\mathrm{Sn}$ and $\mathrm{Zn}$-Ti baths influence kinetics of coatings formations both in terms of coatings thicknesses and of typology of intermetallic phases. Coatings obtained from $\mathrm{Zn}$-Sn bath are characterized by the traditional phases as shown in Fig. 1b, whereas presence of Ti leads to coatings constituted by a $\delta$ phase in the inner layers, and by an outer layer made of three phases. In Fig. 3 kinetics of whole coatings and intermetallic phases thicknesses are shown.

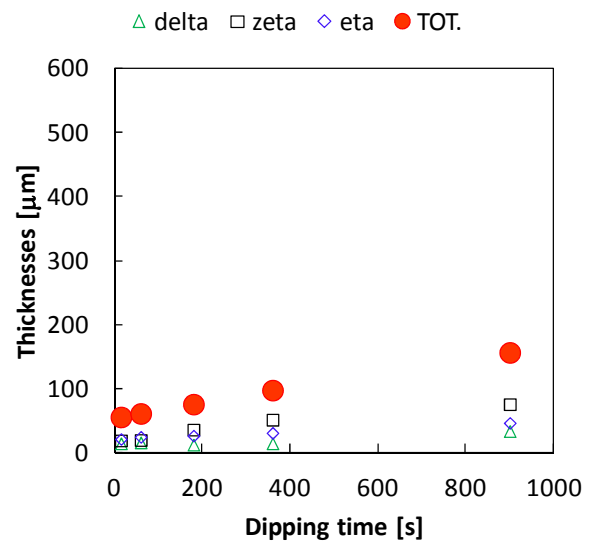

(a)

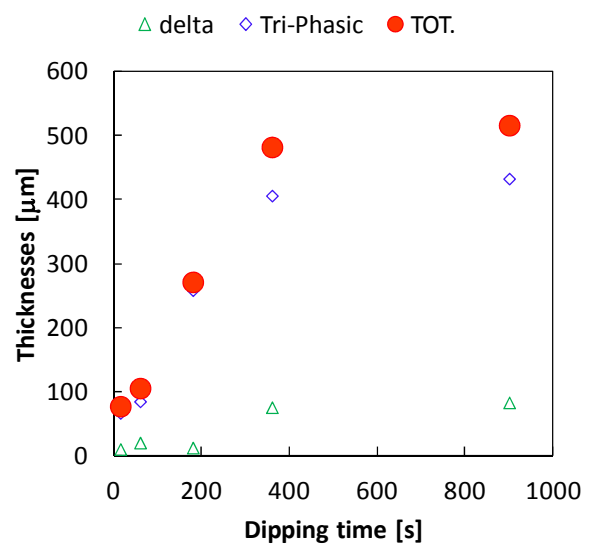

(b)

Figure 3: Coatings and their intermetallic phases thicknesses: a) coatings from $\mathrm{Zn}-\mathrm{Sn}$ bath, b) coatings from Zn-Ti baths.

Presence of $3 \% \mathrm{Sn}$ in the bath covers a linear increase of whole coating thicknesses in the dipping time, while intermetallic $\delta, \zeta$ and $\eta$ phases are characterized by a diffusion phenomenon of growth .

High reactivity of $\mathrm{Zn}$-Ti bath provides to enlarge the thicknesses of whole coatings, as shown in Fig. 3b, where a sharply increase at $360 \mathrm{~s}$ is followed to a weak increase at $900 \mathrm{~s}$. Main parts of coatings are represented by tri-phase zone for all investigated dipping time, whereas $\delta$ phase is characterized by a decrease of thickness from 60 to $180 \mathrm{~s}$, due to interdiffusion between inner and outer zones.

Specimens thickness influences its bending behavior as shown in Fig. 4 where both Zn-Sn and Zn-Ti coatings bending resistance increases with the increasing of dipping time and therefore of its thickness.
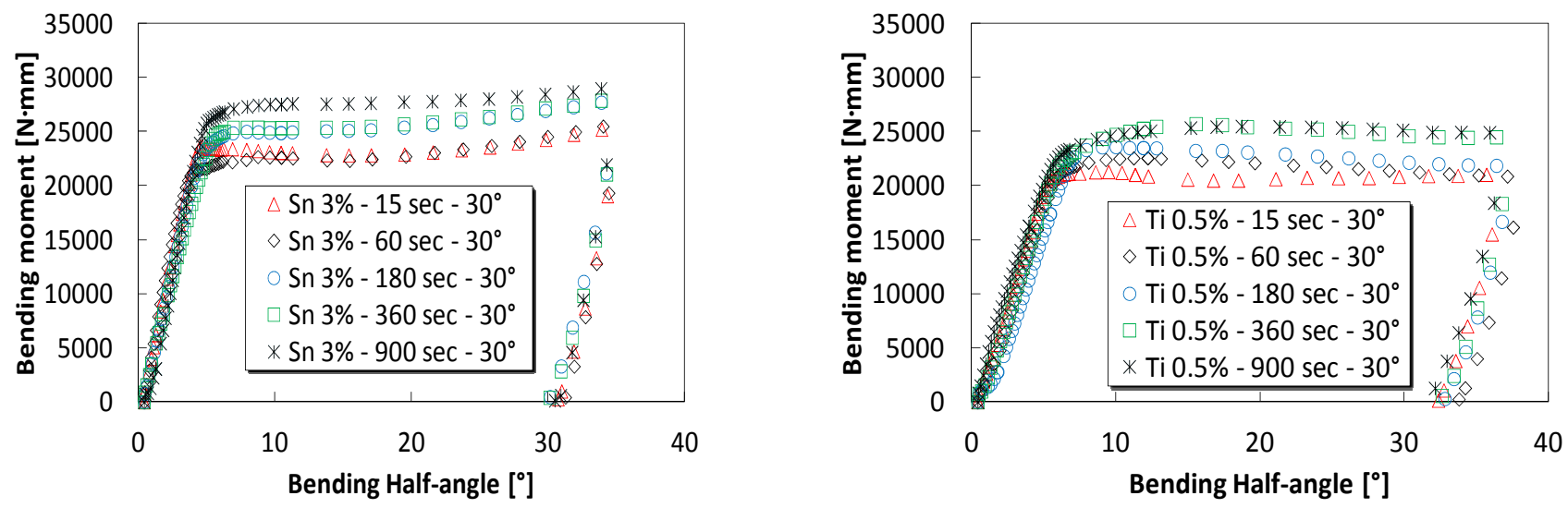

(a)

Figure 4: Bending behavior of galvanized specimens: a) galvanized in Zn-Sn bath, b) galvanized in Zn-Ti bath.

At high values of deformation $\mathrm{Zn}$-Sn coatings show an increase of strength, whereas coatings from Zn-Ti bath show a slight decrease (Fig. 4a and Fig. 4b). Highest values of strength are observed in Zn-Sn coatings. In terms of elastic recovery, coatings from $\mathrm{Zn}-\mathrm{Sn}$ are characterized by a fully recover at investigated deformation, but $\mathrm{Zn}$-Ti coatings show a loss of recover property as shown in Fig. $4 \mathrm{~b}$. 
Tension side

$\stackrel{\infty}{2}$

$\stackrel{\infty}{8}$

$\stackrel{\infty}{\infty}$

is

$\stackrel{\infty}{8}$
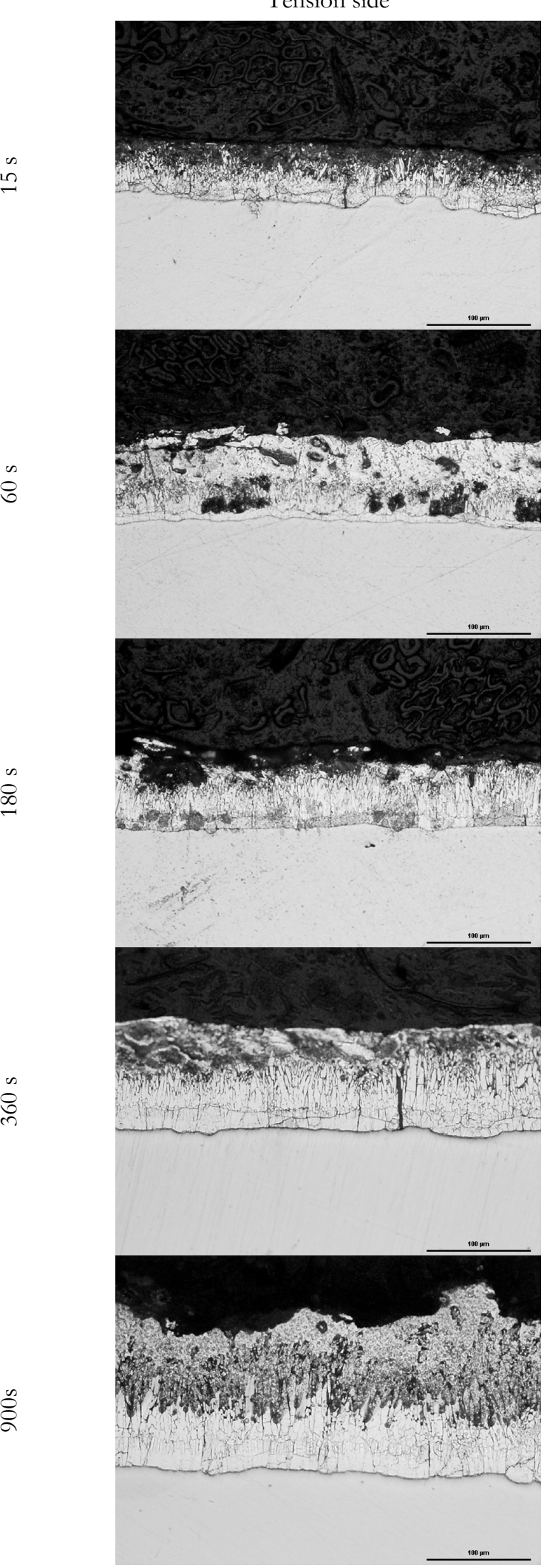

Compression side
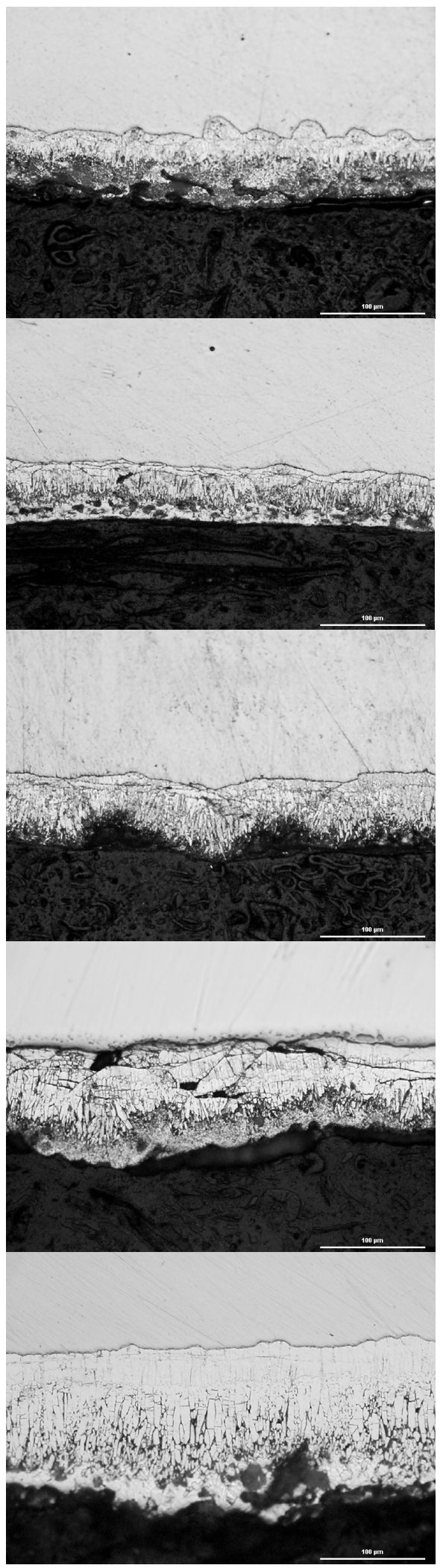

Figure 5: LOM analysis of intermetallic phases damage in $\mathrm{Zn}$-Sn coatings. 
Tension side

in

o

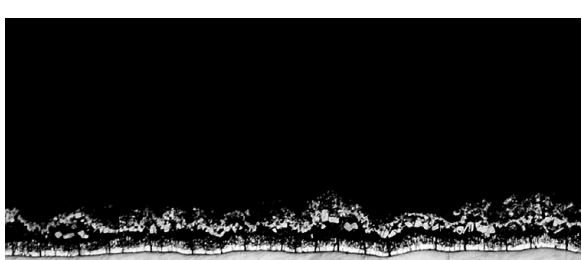

$\stackrel{1000 \mathrm{~mm}}{-}$

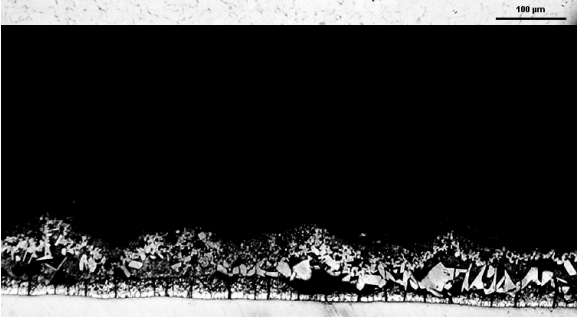

$\stackrel{\infty}{\infty}$

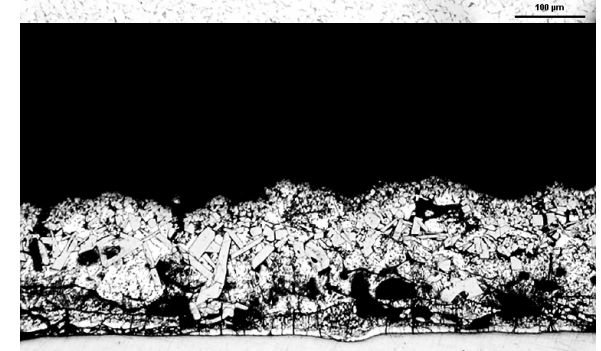

$\underset{n}{\infty}$

$\stackrel{8}{8}$

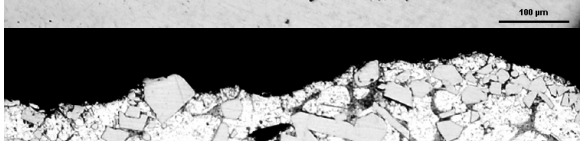

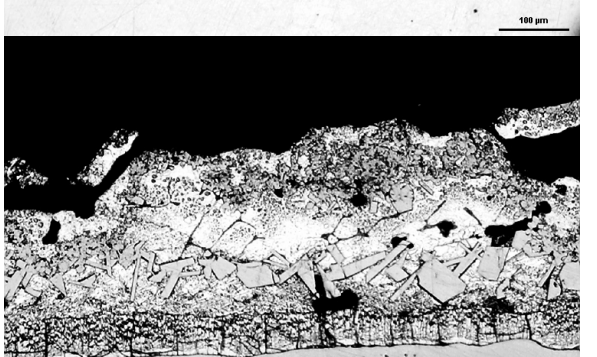

m
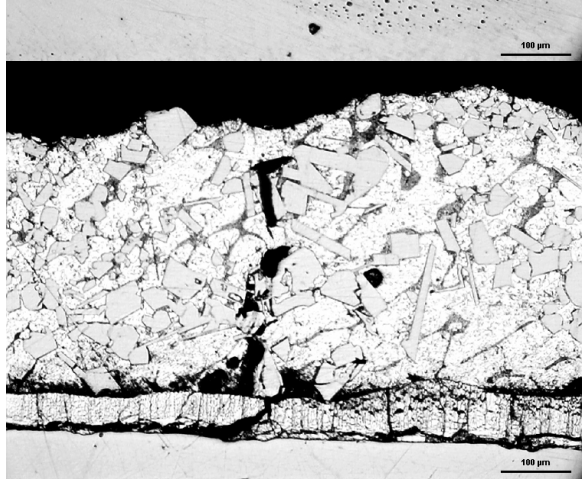

Compression side
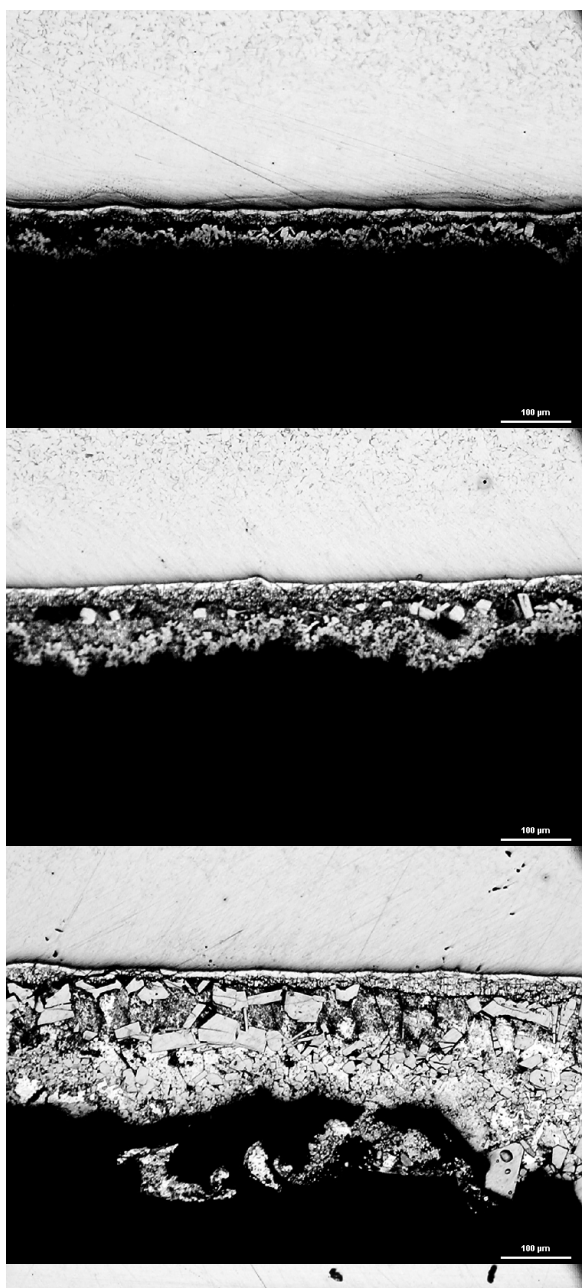

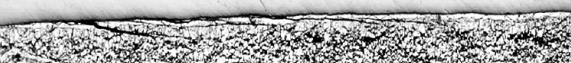

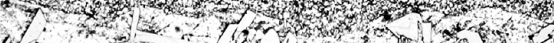

济
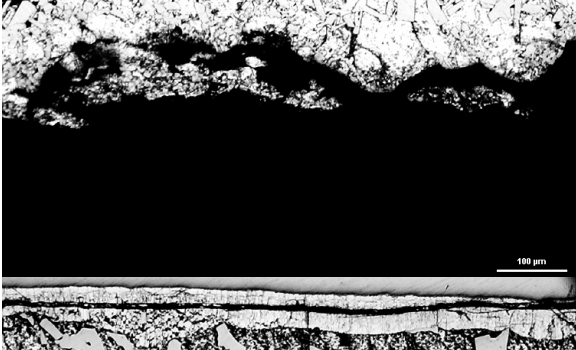

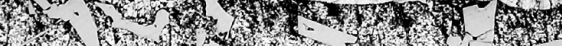
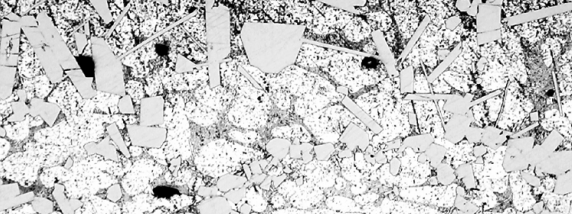

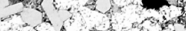

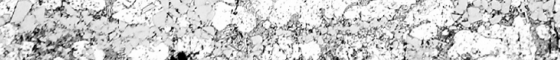

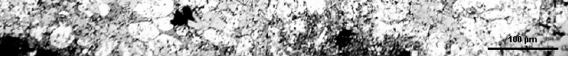

Figure 6: LOM analysis of intermetallic phases damage in $\mathrm{Zn}$-Ti coatings. 
LOM observations of $\mathrm{Zn}-\mathrm{Sn}$ and $\mathrm{Zn}$-Ti coatings sections are shown in Fig. 5 and 6 respectively .

Both $\mathrm{Zn}-\mathrm{Sn}$ and $\mathrm{Zn}$-Ti coatings don't show any damage at low dipping time values in the compression sides, but at high dipping time values it is possible to have a delamination at $\delta-\zeta$ interface (in the $\mathrm{Zn}$-Sn coatings,) or longitudinal cracks in $\delta$ phase in $\mathrm{Zn}$-Ti coatings.

In tension sides of $\mathrm{Zn}$-Ti coatings double longitudinal cracks are present in iron- $\delta$ and $\delta$-tri-phases interfaces, as shown in Fig. 6 at 900s. Furthermore other cracks are present in outer layer, but restricted to one of the three phases constituting outer tri-phases layer. However the main damage in tension sides, for all investigate coatings, is due to the presence of radial cracks. In $\mathrm{Zn}-\mathrm{Sn}$ coatings radial cracks generate at substrate- $\delta$ interface and propagate in $\delta$, arresting at $\delta-\zeta$ interface, or sometimes in $\zeta$ phase or at $\zeta-\eta$ interface while in Zn-Ti coatings radial cracks generate in the substrate- $\delta$ interface and propagate towards outer layer, arresting at interface $\delta$-tri-phases layer.

Radial damage quantification is shown in Fig. 7 in terms of number of radial cracks per millimeter of deformed arc. In $\mathrm{Zn}$ Sn coatings $\delta$ phase is characterized by high values of damage due to its brittle behavior. Moreover, as said above, radial cracks don't start in $\zeta$ phase but propagate from $\delta$.
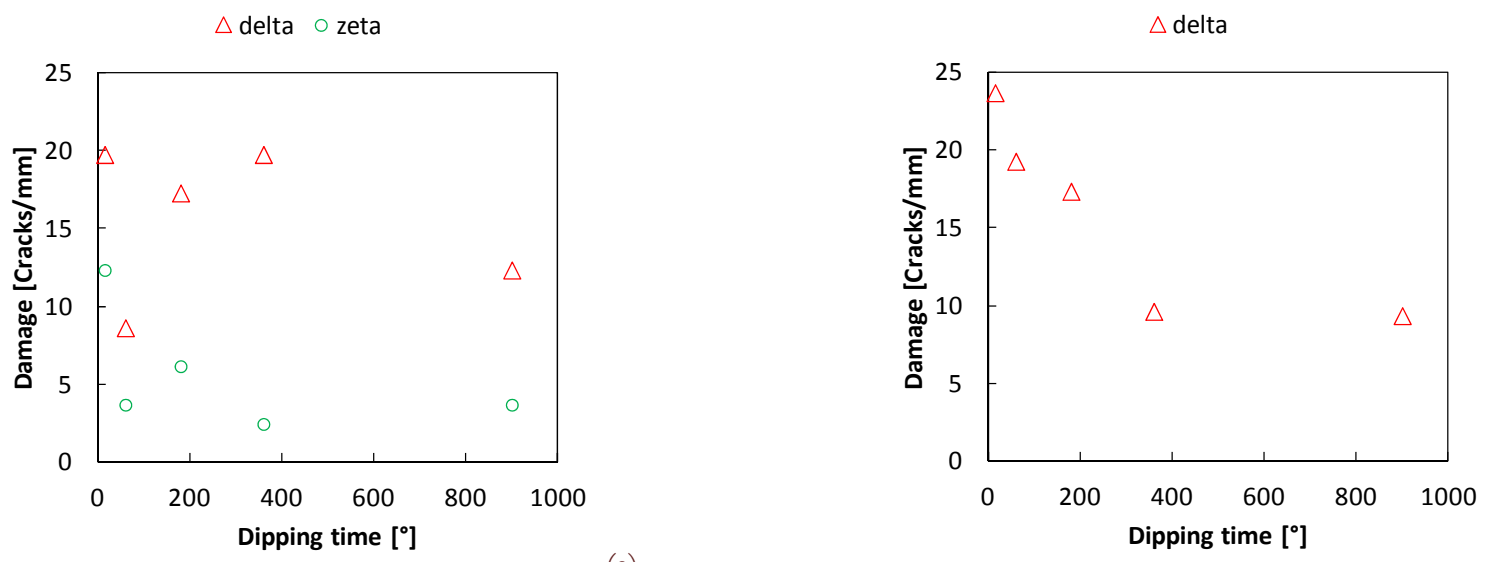

(a)

Figure 7: Intermetallic phases radial damage: a) in Zn-Sn coatings, b) in Zn-Ti coatings.

For those reasons damage level in $\zeta$ phase is lower than the damage level in $\delta$, for all the investigated conditions. In $\mathrm{Zn}$-Ti coatings, radial cracks are present only in $\delta$ phase. In this case damage decreases with dipping time because of the growth of outer layer at 360s, where radial cracks becomes less relevant than the longitudinal ones, which are not given in the chosen damage parameter.

\section{CONCLUSIONS}

I $\mathrm{n}$ this work bending cracks in two Zn-based coatings are investigated in order to evaluate mechanical properties, cracks paths and damage of intermetallic phases.

The presence of Sn doesn't change intermetallic phases characteristic in traditional Zn coatings, but the presence of Ti leads to the presence of an outer zone, formed by a double phases ductile matrix and a brittle dispersed phase.

$\mathrm{Zn}$-Sn coatings are characterized by high bending strength and good elastic recovery properties unlike Zn-Ti coatings, probably due to high values of damage.

In $\mathrm{Zn}-\mathrm{Sn}$, radial cracks initiate at substrate- $\delta$ interface and propagate in $\delta$ phase, arresting at $\delta-\zeta$ interface or in $\zeta$ phase or at $\zeta-\eta$ interface.

In $\mathrm{Zn}$-Ti coatings radial cracks are present in tension side at all investigated dipping time, but beyond 360s longitudinal cracks are the main damage.

\section{REFERENCES}

[1] A.R. Marder: Progress in Materials Science, 45 (2000) 191. 
[2] H.G. Yoon, G.J. AHN, S.J. Kim, M.K. Chung: ISIJ International, 49(11) (2009) 1755.

[3] S.M.A. Shibli, R. Manu: Surface \& Coatings Technology, 201 (2006) 2358.

[4] H. Asgari, M.R. Toroghinejad, M.A. Golozar: ISIJ International, 48(5) (2008) 628.

[5] E. Tzimas, T. Papadimitrou: Surface and Coatings Technology, 145 (2001) 176.

[6] J.L. Duncan, S.-C. Ding, W.L. Jiang: International Journal of Mechanical Sciences, 41 (1999) 249.

[7] J.L. Duncan, S.-C. Ding, W.L. Jiang: International Journal of Mechanical Sciences, 41 (1999) 261.

[8] S.-R. Kim, J.A. Nairn: Engineering Fracture Mechanics, 65 (2000) 573.

[9] S.-R. Kim, J.A. Nairn: Engineering Fracture Mechanics, 65 (2000) 595.

[10] S. Natali, V. Di Cocco, F. Iacoviello: La Metallurgia Italiana, 7-8 (2004) 49.

[11] T. B. Massalski: Binary alloy diagrams, American Society for Metals, Metals Park Ohio 44073, 2 (1987) 2086 and 2140 ISBN 0-87170-263-0. 